\title{
Progress and problems in the biology, diagnostics, and therapeutics of prion diseases
}

\author{
Adriano Aguzzi, Mathias Heikenwalder, and Gino Miele \\ Institute of Neuropathology, University Hospital Zurich, Zurich, Switzerland.
}

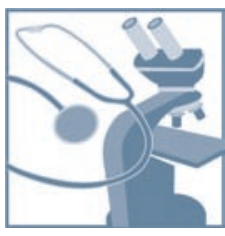

The term "prion" was introduced by Stanley Prusiner in 1982 to describe the atypical infectious agent that causes transmissible spongiform encephalopathies, a group of infectious neurodegenerative diseases that include scrapie in sheep, Creutzfeldt-Jakob disease in humans, chronic wasting disease in cervids, and bovine spongiform encephalopathy in cattle. Over the past twenty years, the word "prion" has been taken to signify various subtly different concepts. In this article, we refer to the prion as the transmissible principle underlying prion diseases, without necessarily implying any specific biochemical or structural identity. When Prusiner started his seminal work, the study of transmissible spongiform encephalopathies was undertaken by only a handful of scientists. Since that time, the "mad cow" crisis has put prion diseases on the agenda of both politicians and the media. Significant progress has been made in prion disease research, and many aspects of prion pathogenesis are now understood. And yet the diagnostic procedures available for prion diseases are not nearly as sensitive as they ought to be, and no therapeutic intervention has been shown to reliably affect the course of the diseases. This article reviews recent progress in the areas of pathogenesis of, diagnostics of, and therapy for prion diseases and highlights some conspicuous problems that remain to be addressed in each of these fields.

\section{Prion pathogenesis, diagnostics, and therapy: where do we stand?}

Prion diseases, also known as transmissible spongiform encephalopathies (TSEs), are invariably fatal neurodegenerative disorders affecting a broad spectrum of host species and arise via genetic, infectious, or sporadic mechanisms (Table 1). In humans, prion diseases result from infectious modes of transmission (variant Creutzfeldt-Jakob disease [vCJD], iatrogenic CJD, Kuru); inherited modes of transmission in which there is nonconservative germ line mutation of the PRNP gene open reading frame (familial CJD, Gerstmann-Sträussler-Scheinker Syndrome, Fatal Familial Insomnia) $(1,2)$; and modes of transmission that have as yet been neither determined nor understood (sporadic CJD [sCJD]). The clinical symptoms associated with each of the human prion disease forms vary dramatically (2).

Nomenclature applied to prion biology continues to be complex and confusing to nonspecialists. Here we utilize the term "prion" to denote the causative agent of prion diseases, without implying associated structural properties. We refer to the disease-associated prion protein $(\mathrm{PrPSc})$, a disease-specific isoform of the host-encod-

Nonstandard abbreviations used: bovine spongiform encephalopathy (BSE); cellular prion protein $\left(\mathrm{PrP}^{\mathrm{C}}\right)$; Creutzfeldt-Jakob disease (CJD); C-terminal transmembrane PrP (CtmPrP); CXC chemokine receptor 5 (CXCR5); cytidyl-guanyl oligodeoxynucleotide (CpG-ODN); days post-inoculation (dpi); disease-associated prion protein $(\mathrm{PrPSc})$; erythroid differentiation-related factor (EDRF); follicular dendritic cell (FDC); LT $\beta$ receptor immunoglobulin fusion protein (LT $\beta \mathrm{R}-\mathrm{Ig}$ ); lymphoreticular system (LRS); lymphotoxin (LT); Prnp knockout (Prnp ${ }^{\mathrm{o} / \mathrm{o}}$ ); Rocky Mountain Laboratory (RML); sporadic Creutzfeldt-Jakob disease (sCJD); toll-like receptor 9 (TLR9); transmissible spongiform encephalopathy (TSE); tyrosine-tyrosine-arginine (YYR); variant Creutzfeldt-Jakob disease (vCJD).

Conflict of interest: The authors have declared that no conflict of interest exists. Citation for this article: J. Clin. Invest. 114:153-160 (2004). doi:10.1172/JCI200422438.

The Science in medicine series is supported in part by a generous grant from the Doris Duke Charitable Foundation. ed cellular prion protein $\left(\mathrm{PrP}^{\mathrm{C}}\right)$, which accumulates in individuals affected with most forms of TSE (Figure 1) (3). While PrPSc is classically defined as partially protease-resistant, aggregated $\operatorname{PrP}$, it has recently been shown that $\mathrm{PrP}^{\mathrm{C}}$ may undergo disease-associated structural modifications that do not impart properties of inherent protease resistance (4). In light of this, it is advisable that $\mathrm{PrP}^{\mathrm{Pc}}$ be defined on the basis of disease-associated structural modifications rather than properties of protease resistance.

Prion diseases are conceptually recent; the first cases of Creutzfeldt-Jakob disease were described eight decades ago $(5,6)$, yet the protein-only theory of prion infection was originally formulated in 1967 (7) and later refined and the term "prion" coined in 1982 (8). The precise physical nature of the prion agent is still the subject of intense scientific controversy. $\mathrm{PrP}^{\mathrm{Sc}}$ may or may not be congruent with the infectious agent. It remains to be formally proven whether the infectious unit consists primarily or exclusively of: (a) a subspecies of $\mathrm{PrP}^{\mathrm{Sc}}$; (b) an intermediate form of $\operatorname{PrP}$ $\left(\mathrm{PrP}^{*}\right)(9)$; (c) other host-derived proteins (10); or (d) nonprotein compounds (which may include glycosaminoglycans and maybe even nucleic acids) (11). We still do not know, therefore, whether the prion hypothesis is correct in its entirety.

As with any other disease, a thorough mechanistic understanding of pathogenesis is the best foundation for devising sensitive predictive diagnostics and efficacious therapeutic regimens.

The purpose of the present article is to discuss some aspects of the state of the art in prion science and their impact on prion diagnostics, primarily with respect to peripherally acquired prion disease. As of now, no causal therapies can be offered to prion disease victims. Yet we are witnessing the emergence of an impressive wealth of therapeutic approaches, some of which certainly deserve to be tested for their validity.

\section{Progress in understanding prion pathogenesis}

Prion pathogenesis is a dynamic process that can be broken down into spatially and temporally distinct phases: (a) infection and 
Table 1

Spectrum of prion diseases of humans and animals

$\begin{array}{lcc}\text { Prion disease } & \text { Natural host species } & \text { Etiology } \\ \text { SCJD } & \text { Humans } & \text { Unknown (somatic PRNP mutation?) } \\ \text { Familial Creutzfeldt-Jakob disease (fCJD) } & \text { Humans } & \text { Familial (germ line PRNP mutation) } \\ \text { latrogenic Creutzfeldt-Jakob disease (iCJD) } & \text { Humans } & \text { Surgical procedures (infection) } \\ \text { VCJD } & \text { Humans } & \text { Ingestion of BSE-contaminated food; transfusion medicine (infection) } \\ \text { Kuru } & \text { Humans } & \text { Ingestion, ritualistic cannibalism (infection) } \\ \text { Fatal Familial Insomnia (FFI) } & \text { Humans } & \text { Familial (germ line PRNP mutation) } \\ \text { Gerstmann-Sträussler-Scheinker Syndrome } & \text { Humans } & \text { Familial (germ line PRNP mutation) } \\ \text { Scrapie } & \text { Sheep, goats } & \text { Infection, natural; mode of transmission unclear } \\ \text { Chronic Wasting Disease (CWD) } & \text { Deer, Elk } & \text { Infection; mode of transmission unclear } \\ \text { BSE } & \text { Cattle } & \text { Ingestion of BSE-contaminated feed (infection) } \\ \text { Transmissible mink encephalopathy } & \text { Mink } & \text { Ingestion (infection); Origin unclear } \\ \text { Feline spongiform encephalopathy } & \text { Cats } & \text { Ingestion of BSE-contaminated feed (infection) } \\ \text { Spongiform encephalopathy of zoo animals } & \text { Zoologic bovids, primates } & \text { Ingestion of BSE-contaminated feed (infection) } \\ \end{array}$

peripheral replication; (b) transmigration from the periphery to the CNS (also termed "neuroinvasion"); and (c) neurodegeneration. But what are the mechanisms underlying neuroinvasion, and which cellular compartments are involved in replication and neuroinvasion of prions?

\section{Peripheral replication}

Cell tropism of prions varies dramatically among animal species and is also in part dependent on the particular strain of prion agent. For example, prions are lymphotropic in sheep scrapie and $\mathrm{vCJD}$ (12) but less so in sCJD (13) and bovine spongiform encephalopathy (BSE). Different prion strains can lead to different routes of peripheral replication in experimental models of scrapie $(14,15)$, and, therefore, strain-encoded properties might also determine the route of peripheral replication. With respect to peripheral pathogenesis of prion diseases, it is well established that replication of the prion agent occurs in high titers in lymphoid tissues such as spleen and lymph nodes well before neuroinvasion and subsequent detection in the CNS (16).

Upon oral challenge, an early rise in prion infectivity is observed in the distal ileum of infected organisms. This applies to several species but has been most extensively investigated in sheep, and Western blot analyses and bioassays have shown that Peyer's patches accumulate $\mathrm{PrP}^{\mathrm{Sc}}$ and contain high titers of prion infectivity. This is true also in the mouse model of scrapie, where administra-

Figure 1 monomer addition is accelerated. tion of mouse-adapted scrapie prions (Rocky Mountain Laboratory $[\mathrm{RML}]$ strain) induces a surge in intestinal prion infectivity as early as a few days after inoculation $(17,18)$. Indeed, immune cells are crucially involved in the process of neuroinvasion after oral application: mature follicular dendritic cells (FDCs), located in Peyer's patches, may be critical for the transmission of scrapie from the gastrointestinal tract $(16,18)$.

\section{Neuroinvasion}

The resistance to prions of mice that lack expression of $\mathrm{PrP}^{\mathrm{C}}$, encoded by Prnp (a single-copy gene located on chromosome 2 in mice and 20 in humans), is well documented $(19,20)$. While the

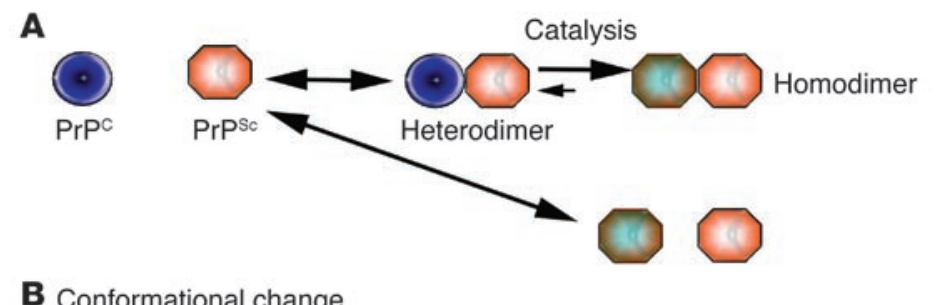

B Conformational change

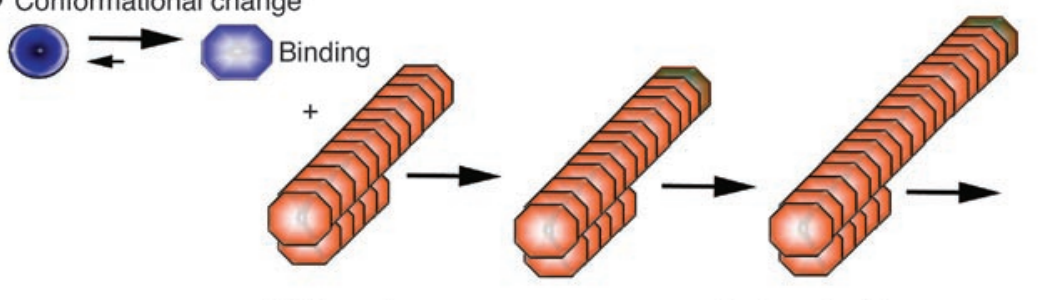

PrPsceed

Polymerization

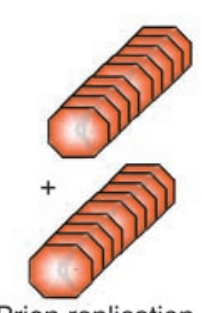

Prion replication by fragmentation

Models of PrPC to PrPsc conversion. (A) The heterodimer model proposes that upon infection of an appropriate host cell, the incoming PrPsc (orange) starts a catalytic cascade using PrPc (blue) or a partially unfolded intermediate arising from stochastic fluctuations in $\mathrm{PrPC}^{\mathrm{C}}$ conformations as a substrate, converting it by a conformational change into a new $\beta$-sheet-rich protein. The newly formed PrPsc (green-orange) will in turn convert new PrPC molecules. (B) The noncatalytic nucleated polymerization model proposes that the conformational change of $\mathrm{PrPC}^{\mathrm{C}}$ into $\mathrm{PrPsc}^{\mathrm{S}}$ is thermodynamically controlled: the conversion of $\operatorname{PrP}^{\mathrm{C}}$ to $\mathrm{PrPSc}$ is a reversible process but at equilibrium strongly favors the conformation of $\mathrm{PrPc}$. Converted $\mathrm{PrPSc}$ is established only when it adds onto a fibril-like seed or aggregate of PrPsc. Once a seed is present, further 


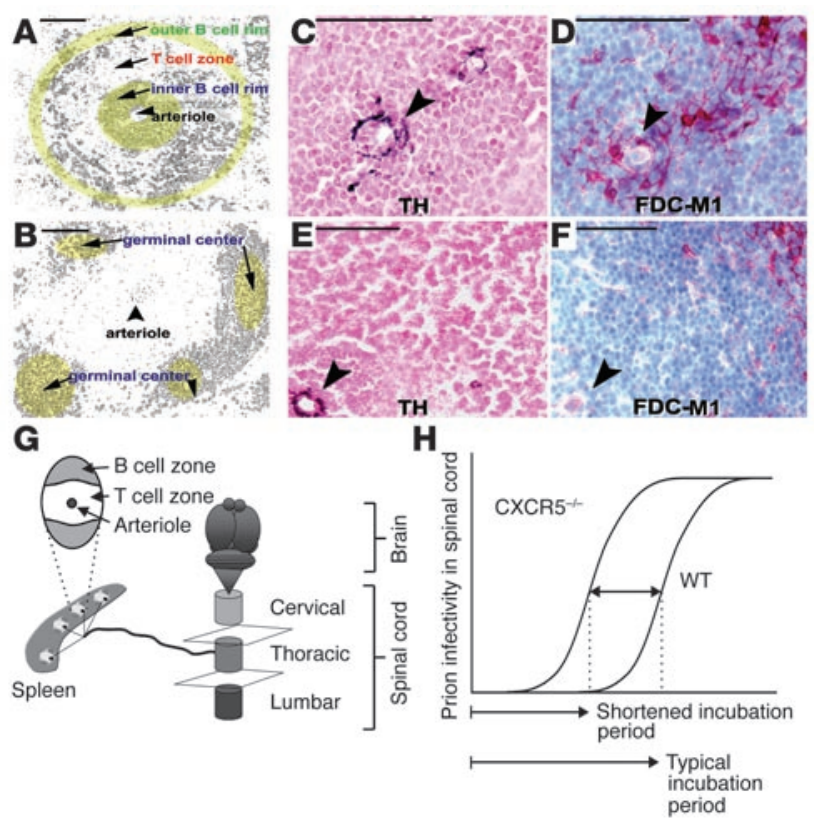

Figure 2

Positioning of FDCs in spleens of WT and CXCR5 $5^{-/-}$mice. (A and $\mathbf{B}$ ) Diagrammatic representation of white pulp follicles in prion-infected CXCR5 $^{-1-}$ and WT mice. Anti-CD21 immunostaining was performed to visualize the lymphoid white pulp follicle microarchitecture. (C) Atypically localized perivascular FDCs in lymph follicles in CXCR5 $5^{-1-}$ mice. Sympathetic nerves, visualized with antibodies to tyrosine hydroxylase (TH), are in close vicinity to FDCs (visualized by FDC-M1 immunostaining) (D). Scale bar: $50 \mathrm{~mm}$. In contrast, sympathetic nerves in WT FDCs are localized in $B$ cell areas at the periphery of the follicles (E and $\mathbf{F}$ ). Arrowheads indicate TH and FDC-M1 positive areas. (G) Sympathetic nerves lining the thoracic spinal cord connect lymphoid organs and the CNS. (H) Shortened prion disease incubation period in CXCR5 $5^{-/-}$mice inoculated intraperitoneally, relative to WT controls.

precise physiological function of $\mathrm{PrP}^{\mathrm{C}}$ is unclear, expression of it is absolutely required for transportation of the infectious agent both from the peripheral sites to the CNS (21) and within the CNS (22). However, reconstitution of Prnp knockout $\left(\operatorname{Prnp}^{\mathrm{o} / \mathrm{o}}\right)$ mice with WT bone marrow is insufficient to restore neuroinvasion in Prnpo/o mice (21). Hence one could argue that the elemental compartment required for prion neuroinvasion is stromal and must express $\mathrm{PrP}^{\mathrm{C}}$. Nevertheless, in adoptive transfer experiments on Prnpo/o mice with WT bone marrow, the capability of the spleen to accumulate prions of the RML strain is restored $(21,23)$. This suggests that hematopoietic cells transport prions from the entry site to the lymphoreticular system (LRS), which accumulates and replicates prions. B lymphocytes (not necessarily expressing $\mathrm{PrP}^{\mathrm{C}}$ ) are crucial for peripheral prion spread and neuroinvasion (24-26).

This dependence of FDCs on lymphotoxin (LT) signaling by B cells likely may explain - at least in part - the apparent requirement for B cells in peripheral pathogenesis: FDCs have been reported to accumulate PrPSc following scrapie infection (27). Indeed, blockade of LT signaling via administration of a soluble, dimeric LT $\beta$ receptor immunoglobulin fusion protein (LT $\beta$ R-Ig) ablates mature FDCs and significantly impairs peripheral prion pathogenesis $(28,29)$.

FDCs are bifunctional cells: they support the formation and maintenance of the lymphoid microarchitecture but also play a role in antigen trapping - capturing immune complexes by Fc $\gamma$ receptors and binding opsonized antigens to the CD21/CD35 complement receptors. Two studies have demonstrated that the complement system is relevant to prion pathogenesis. Mice genetically engineered to lack complement factors (30) or mice depleted of the C3 complement component (31) exhibited enhanced resistance to peripheral prion inoculation. However, FDCs are most likely immobile cells and therefore unlikely to be responsible for prion transport into the CNS.

But just which cell types are involved in neuroinvasion? The innervation pattern of lymphoid organs is primarily sympathetic (32). Sympathectomy delays the onset of scrapie, while sympathetic hyperinnervation enhances splenic prion replication and neuroinvasion, which suggests that innervation of secondary lymphoid organs is the rate-limiting step to neuroinvasion (33). However, there is no physical synapse between FDCs and sympathetic nerve endings (34). So how can prions transmigrate from FDCs to sympathetic nerve fibers? A series of recent experiments (discussed below) may go some way toward providing answers.

\section{FDC positioning is a primary determinant of velocity of neuroinvasion}

We investigated how the distance between FDCs and splenic nerves affects the velocity of neuroinvasion, utilizing mice deficient in the CXC chemokine receptor 5 (CXCR5), which directs lymphocytes toward specific microcompartments (35). While density, distribution, and branching patterns of sympathetic nerve processes in $\mathrm{CXCR5}^{-/}$spleens are normal, the distance between FDCs and nerve endings is greatly reduced (36).

After peripheral administration of high doses of prions, velocity of pathogenesis was similar in CXCR5 ${ }^{-/-}$and WT mice; however, delivery of smaller inocula resulted in a dose-dependent increase in incubation periods in WT mice that was not evident in CXCR5/mice. Peripheral prion pathogenesis in $\mathrm{CXCR}^{-/-}$mice is therefore more efficient upon incremental reduction of the inoculum.

What is the basis of this reduced incubation period? Kinetics measurements of prion infectivity titers in the thoracic spinal cord provided the answer: following peripheral administration, only traces of infectivity were found in WT spinal cords at 80 days postinoculation (dpi), whereas infectivity rose to measurable levels in the spinal cords of $\mathrm{CXCR}^{-/-}$mice already at $60 \mathrm{dpi}$. This suggests that increased velocity of prion entry into the CNS in CXCR5 ${ }^{-/-}$ mice is due to the repositioning of FDCs near highly innervated, splenic arterioles (Figure 2). This was validated by the finding that incubation periods were prolonged in $\mathrm{CXCR}^{-/-}$mice treated with soluble LT $\beta$ R-Ig to deplete mature FDCs.

Hence topographical relationships within lymphoid organs contribute to prion neuroinvasion. However, it remains to be determined whether this results from passive diffusion of prions or whether mobile cells (e.g., germinal center B cells) are involved in an active transport process.

This study also raises the possibility that spread of infection to peripheral nerves occurs more rapidly when FDCs are in close proximity to nerves in lymphoid tissue other than spleen, such as Peyer's patches. Indeed, FDCs are crucial to disease progression but only during a short window of time following oral scrapie challenge (17). This implicates the efficiency of neuroimmune transfer of prions as a primary determinant of neuroinvasion. The detection of $\mathrm{PrPSc}^{\mathrm{S}}$ in spleens of SCJD patients (12) suggests that the interface between cells of the immune system and 
Table 2

Molecular diagnosis of prion disease and prion infectivity

\begin{tabular}{|c|c|c|c|c|}
\hline & Method & Diagnostic principle & Platform & Properties \\
\hline \multirow[t]{6}{*}{ Disease-associated PrP } & Prionics-Check, Western blot & PrPsc & Western blot & $\begin{array}{l}\text { Very high specificity, } \\
\text { medium throughput }\end{array}$ \\
\hline & Prionics-Check LIA & PrPsc & ELISA & High throughput \\
\hline & Bio-Rad ELISA & PrPsc & ELISA & High throughput \\
\hline & Enfer Scientific TSE kit & PrPSc & ELISA & High throughput \\
\hline & $\begin{array}{l}\text { InPro Biotechnology } \\
\text { CDI }\end{array}$ & $\begin{array}{c}\text { PrPsc and protease-sensitive } \\
\text { PrPSc }\end{array}$ & ELISA & High throughput \\
\hline & Anti-YYR motif mAb's & PrPSc & Immunoprecipitation & May obviate proteolytic digest \\
\hline Genetic tests & & PRNP ORF mutation & DNA sequencing & $\begin{array}{l}\text { Unambiguous diagnosis } \\
\text { of predisposition }\end{array}$ \\
\hline Surrogate markers & & $\begin{array}{c}\text { 14-3-3 } \\
\text { Blood EDRF levels }\end{array}$ & $\begin{array}{l}\text { Western blot, ELISA } \\
\text { Northern blot, RT-PCR }\end{array}$ & $\begin{array}{l}\text { Positive in cerebrospinal fluid } \\
\text { Extraneural diagnostics }\end{array}$ \\
\hline \multirow[t]{4}{*}{ Prion infectivity assays } & Endpoint bioassay & Prion infectivity & Transmission to mice & $\begin{array}{l}\text { Highly sensitive and } \\
\text { precise, long incubation } \\
\text { times, extremely costly }\end{array}$ \\
\hline & Bioassay by incubation time & Prion infectivity & Transmission to mice & $\begin{array}{l}\text { High sensitivity, } \\
\text { imprecise, very costly }\end{array}$ \\
\hline & Scrapie cell assay & Prion infectivity & Transmission to cells & $\begin{array}{l}\text { High sensitivity, } \\
\text { currently medium throughput, } \\
\text { only available for mouse prions }\end{array}$ \\
\hline & $\begin{array}{c}\text { Scrapie cell assay } \\
\text { in endpoint format (SCEPA) }\end{array}$ & Prion infectivity & Transmission to cells & $\begin{array}{l}\text { High sensitivity and } \\
\text { precision, low throughput }\end{array}$ \\
\hline
\end{tabular}

All currently reported methods of assessing the presence of prion disease are listed, including validated methods and nonvalidated experimental approaches. Most commercial assays rely on the direct detection of disease-associated PrPSc. LIA, luminescence immunoassay; CDI, conformation-dependent immunoassay. ORF, open reading frame.

peripheral nerves (the neuroimmune connection) might also be of relevance in sporadic prion disease.

\section{The neurodegeneration issue}

There has certainly been progress in understanding the events underlying peripheral prion pathogenesis and neuroinvasion (37). However, prions exert their destructive effects exclusively within the CNS. The precise cause of neurodegeneration remains poorly understood and is a point of contention among prionologists. It seems unlikely that $\mathrm{PrPSc}^{\mathrm{Sc}}$ is directly toxic, since tissue devoid of $\mathrm{PrP}^{\mathrm{C}}$ that subsequently accumulates $\mathrm{PrPS}$ remains healthy and free of pathology $(20,38)$. During the conversion process, $\mathrm{PrP}^{\mathrm{C}}$ levels may be depleted, yet this is also an unlikely cause of pathology, since ablation of $\mathrm{PrPC}^{\mathrm{C}}$ does not result in scrapie-like symptoms (39), even when ablated postnatally (40).

Lindquist and colleagues have suggested a mechanism that may account for prion-associated toxicity: (a) expression of a PrP variant resident in the cytosol was strongly neurotoxic in cultured cells and transgenic mice, which suggests a common framework for diverse PrP neurodegenerative disorders (41); and (b) PrP, retrogradely transported out of the endoplasmic reticulum, produced amorphous aggregates of PrP possessing partial proteinase $\mathrm{K}$ resistance in the cytosol. Once conversion occurred, it was self-sustaining (42). It will be interesting to determine whether the disease generated in these mice is, in some way, transmissible. However, while the results obtained here are certainly intriguing, it should be noted that reports elsewhere, although not refuting these observations, argue against the contribution of such potential neurotoxic PrP species (43,
44). Similarly, it has been reported that $\mathrm{PrPC}^{\mathrm{C}}$ in some forms of prion disease assumes a transmembrane topology, C-terminal transmembrane $\operatorname{PrP}(\mathrm{Ctm} P r P)$, and that the extent of neurotoxicity is a result of concentration of ${ }^{C t m} \operatorname{PrP}$, thereby arguing that Ctm PrP may represent a major toxic moiety $(45,46)$. However, while we still do not understand the biochemical events involved in cytosolic or CtmPrP-induced neurotoxicity, elucidation of this may aid in the much-needed identification of therapeutic targets. Additionally, in-depth characterization of transgenic mice expressing amino-terminally truncated $\operatorname{PrP}^{\mathrm{C}}(47)$, in which cerebellar neurodegeneration occurs, may not only aid in the elucidation of the molecular events responsible for potentially common neurodegenerative processes but perhaps also provide clues to the physiological function of $\mathrm{PrPC}^{\mathrm{C}}$ itself.

\section{Prion diagnostics}

The ability to secure early diagnosis is vital for therapeutic interventions to be of real value. With respect to animals destined for the human food chain, there is the additional demand to determine presence of the prion agent in tissues in asymptomatic organisms, well before the appearance of any clinical symptoms. This applies equally to the detection of prions in humans, who may participate in tissue donation programs.

Prions were transmitted via blood transfusion in sheep using blood obtained from infected animals prior to the onset of clinical symptoms $(48,49)$. If the same route applies to humans, this could represent a nightmare scenario for the blood transfusion services (50). A transfusion recipient received blood from an individual harboring the vCJD agent 3.5 years prior to the development of 
any clinical signs of prion disease in the donor. The unfortunate recipient developed disease 6.5 years after the transfusion.

\section{Detection of PrPSc}

To be truly useful, prion diagnostics should identify "suspect" cases as early during pathogenesis as possible. However, the currently available methods are quite insensitive when compared with those available for other infectious diseases. $\mathrm{PrPSc}^{\mathrm{Sc}}$ represents the only disease-specific macromolecule identified to date, and all approved commercial testing procedures are based on the immunological detection of $\mathrm{PrP}^{\mathrm{Sc}}$. While around 50 companies are reported to be developing prion diagnostic assays, all commercial test kits validated for use by the European Union rely on proteolytic removal of endogenous $\mathrm{PrPC}^{\mathrm{C}}$ prior to detection of $\mathrm{PrPSc}$ (Table 2). In addition, the conformation-dependent immunoassay (4) utilizes the differential binding of antibodies to native or denatured $\mathrm{PrP}^{\mathrm{Sc}}$.

Circumvention of the protease digestion step might theoreti-

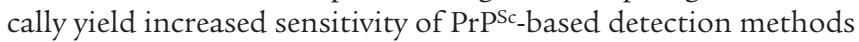
and make these methods more amenable to high-throughput technologies. However, it has proved difficult to discriminate between $\mathrm{PrP}^{\mathrm{C}}$ and $\mathrm{PrP}^{\mathrm{Sc}}$ with antibodies, despite some early reports (51). Interestingly, tyrosine-tyrosine-arginine (YYR) motifs (52) were reasoned to be more solvent-accessible in the pathological isoform of $\mathrm{PrP}$, and a monoclonal antibody directed against these motifs was reported to be capable of selectively detecting $\mathrm{PrP}^{\mathrm{Sc}}$ across a variety of platforms. However, YYR motifs are certainly not unique to pathological prion proteins, and it remains to be determined whether this reagent can really improve the sensitivity of detection of prion infections.

Deposition of $\mathrm{PrP}^{\mathrm{Sc}}$ in lymphoid tissues of human prion disease patients has long been believed to be restricted to vCJD. However, recent results (12) imply that $\mathrm{PrPSc}^{\mathrm{Sc}}$ is present in spleens and muscle tissue from as much as one third of patients with sCJD. It is presently unclear whether the patients with extraneural PrP represent a specific subset of CJD patients or whether the extraneural-negative patients may simply deposit $\mathrm{PrPsc}^{\mathrm{Sc}}$ in muscle and spleen at levels that are below the detectability threshold of the assay. If the latter scenario proves true, and if the assay sensitivity can be raised, minimally invasive muscle biopsies may replace brain biopsy in clinical CJD diagnostics.

\section{Surrogate markers and prion infectivity}

While presence of $\mathrm{PrP}^{\mathrm{Sc}}$ secures diagnostic association with the presence of prion disease, $\mathrm{PrPSc}^{\mathrm{S}}$ is not always easily detectable in several forms of prion disease (53-55). In order to enhance the safety of the blood supply and of products of bovine origin, absolute specificity in securing diagnosis of asymptomatic prion disease may not be required. Instead, it may be prudent to accommodate less than $100 \%$ specificity with a panel of surrogate markers capable of identifying donated blood units from "suspect" individuals rather than requiring definitive diagnosis. It could be envisaged that wide-scale primary screens accommodate a certain degree of loss of specificity to identify samples to be re-tested in a secondary screen utilizing more specific (and likely labor-intensive) criteria.

Several research efforts have been directed at identifying transcripts and proteins differentially expressed in tissues of prioninfected animals relative to disease-free controls (56-58). However, these have mostly focused primarily either on prion-infected neural cell lines or on CNS tissue, frequently with emphasis on late-stage disease. Ideally, these surrogate markers should be detectable (and differentially expressed) in easily accessible body fluids, such as blood or urine. At present, only one extraneural gene was reported to be differentially expressed during prion infection (59): erythroid differentiation-related factor (EDRF; also known as erythroidassociated factor) levels were progressively reduced in spleens of prion-infected mice throughout pathogenesis and also in blood of experimentally infected mice, cattle with BSE, and sheep with clinically manifest scrapie.

Assessment of the levels of surrogate markers in healthy individuals is crucial in order to define the normal range of expression (according to age, sex, etc.) in order to determine what represents abnormal levels. In this respect, it is worth noting that determination of normal expression range must utilize appropriate controls. For example, EDRF transcript levels have recently been reported to show a broad range of variation in healthy human subjects (60). However, since EDRF is an erythroid-specific transcript, it would be imperative to utilize other erythroid transcripts as internal controls to normalize for variations in numbers of circulating cells in which the transcript under study is expressed relative to total cells. More searches for surrogate markers would certainly be useful, and it is likely that surrogate markers of prion disease, particularly if they are detectable in body fluids, will expand the panel of tools available for screening for prion infections.

It is also worth noting here that recent advances in neuroimaging techniques, particularly with respect to MRI, may lead to clinically useful methods of assessment of prion disease in humans, perhaps even the ability to distinguish between sCJD and vCJD (61). For example, in vCJD the pulvinar sign (a high T2 MRI signal in the posterior thalamus) has been suggested to be relatively specific for $\mathrm{vCJD}$, being present in approximately $75 \%$ of vCJD patients tested (62). In sCJD, fluid-attenuated inversion recovery and diffusionweighted MRI sequences appear to be associated with high sensitivity and specificity. MRI imaging techniques such as these may therefore represent a relatively noninvasive method to corroborate suspicion of clinical presentation of human prion disease.

While surrogate markers such as S-100, neuron-specific enolase, and 14-3-3 protein have been suggested as potential biomarkers of prion disease using body fluids such as cerebrospinal fluid (CSF) $(63,64)$, it is worth remembering that these are clearly surrogate markers of general neurodegenerative disease and are not therefore predictive for human prion disease. For example, one study reported false positives of 14-3-3 detection in CSF samples of patients with herpes simplex encephalitis, hypoxic brain damage, atypical encephalitis, intracerebral metastases of a bronchial carcinoma, and metabolic encephalopathy (65).

It should not be forgotten that there is no ultimate consensus on the nature of the prion: $\mathrm{PrP}^{\mathrm{Sc}}$ itself might represent a surrogate marker of prion disease (66). The real gold standard of prion diagnostics is the detection of prion infectivity (whether or not $\mathrm{PrP}^{\mathrm{Sc}}$ is present). Until recently, the only method available to assay for prion infectivity was the use of the mouse bioassay, in which serial dilutions of test material are inoculated into mice and onset of disease noted. However, this procedure suffers from inaccuracy and is limited by the requirements for scores of mice and significant lengths of time. Recently, the use of highly susceptible cloned neural cell lines has provided what appears to be an assay that delivers a substantial reduction in both cost and time required to perform prion bioassays and may lend itself to high-throughput automation (67). Such assays may advance methodologies aimed at diagnostic assessment of the presence of 
Table 3

Approaches to prion therapy

\begin{tabular}{|c|c|c|c|}
\hline Therapeutic approach & Target & Properties & References \\
\hline Polyanions & Possibly membrane-resident PrPsc & $\begin{array}{l}\text { Efficient in cultured cells; } \\
\text { relatively toxic in vivo }\end{array}$ & $(70,88)$ \\
\hline Curcumin & Unknown & Efficacy in vivo unproven & (74) \\
\hline Soluble lymphotoxin receptor & FDCs & $\begin{array}{l}\text { Effective in vivo, but only on peripheral } \\
\text { pathogenesis; moderate untoward effects }\end{array}$ & $(28,29)$ \\
\hline CpG oligodeoxynucleotides & FDCs, DCs; B cells and macrophages & Severely immunoclastic at doses effective in vivo & $(76,79)$ \\
\hline Anti-PrP antibodies & PrPc & Effective in vivo only if administered in massive doses & $(80,83,84)$ \\
\hline $\begin{array}{l}\text { Amyloidotropic intercalators } \\
\text { (e.g., Congo red) }\end{array}$ & PrPSc & Toxic; questionable efficacy in vivo & $(89,90)$ \\
\hline $\begin{array}{l}\text { Chemical or immunological } \\
\text { sympathectomy }\end{array}$ & $\begin{array}{l}\text { Peripheral nerves involved } \\
\text { in neuroinvasion }\end{array}$ & $\begin{array}{l}\text { Very efficacious, but unacceptable } \\
\text { toxicity in vivo }\end{array}$ & $(33)$ \\
\hline Polyene antibiotics & Possibly membrane-resident PrPsc & Low efficacy in vivo & $(91,92)$ \\
\hline Chlorpromazine and quinacrine & Unknown & Questionable efficacy in vivo; hepatotoxicity & $(93-95)$ \\
\hline $\begin{array}{l}\text { Soluble dimeric PrPc } \\
\text { immunoadhesin }\end{array}$ & PrPSc & $\begin{array}{l}\text { Effective as transgene, but efficacy } \\
\text { upon injection unproven }\end{array}$ & $(87)$ \\
\hline
\end{tabular}

While most substances investigated so far may possess prion-curing potential in vitro, no effective therapeutic substance has been identified so far for actual in-vivo therapy in humans. However, fusion proteins either antagonizing soluble prion protein or depleting mature FDCs have been shown to efficiently prolong the incubation time of infected animals.

the prion agent. However, it should be noted that these cell lines are currently reported only to be permissive to murine prions. It is to be expected that the spectrum of prion strains that can be assayed using this technology will expand.

\section{Prion therapy}

For all the promising approaches that are being explored (Table 3), no therapy for prion diseases is available as of yet. Many substances appear to possess prion-curing properties in vitro, including Congo red (68), amphotericin B, anthracyclines (69), sulfated polyanions (70), porphyrins (71), branched polyamines (72), -sheet breakers (73), the spice curcumin (74), and recently even small interfering RNAs (75). The majority of these molecules exert their biological effects by directly or indirectly interfering with conversion of $\mathrm{PrP}^{\mathrm{C}}$ to $\mathrm{PrPS}^{\mathrm{Sc}}$, thereby also aiding clearance of $\mathrm{PrP}^{\mathrm{Sc}}$. Yet none of these compounds have proved very effective for actual therapy.

In a recent report, results obtained in mice have led to the theory that administration of cytidyl-guanyl oligodeoxynucleotides (CPGODNs), which stimulate the innate immune system via toll-like receptor 9 (TLR9) signaling receptors on a variety of immune cells, may represent an applicable treatment regimen to delay prion disease in humans (76). Here it was shown that the incubation period of prion disease was extended in mice multidose treated with CpGODNs for twenty days. It was concluded that stimulation of innate immunity accounts for this apparent anti-prion effect, possibly through induction of anti-PrP antibodies. However, this is difficult to reconcile with several studies indicating that immune deficiencies of various sorts inhibit prion pathogenesis $(24,25,30,77)$. In addition, prion pathogenesis is unhampered in $\mathrm{MyD}^{-/-}$mice, in which there is impaired TLR9 signaling (78). In fact, repeated CpG-ODN treatment has severe side effects, ranging from lymphoid follicle destruction and impaired antibody class switch to the development of ascites, hepatotoxicity, and thrombocytopenia (79). In addition, anti-PrP antibodies are not detectable in CpGODN-treated mice (79). It is likely therefore that the anti-prion effects of repeated CPG-ODN treatment arise via indiscriminate and undesirable follicular destruction.

\section{Is vaccination against prion disease possible?}

Anti-PrP antibodies (30) and F(ab) fragments to $\operatorname{PrP}(80,81)$ can suppress prion replication in cultured cells. However, the mammalian immune system is essentially tolerant to $\operatorname{PrPC}^{\mathrm{C}}(82)$. Ablation of Prnp (39) renders mice highly susceptible to immunization with prions (22). Tolerance can be circumvented by transgenic expression of an immunoglobulin $\mu$ chain containing the epitope-interacting region of a high-affinity anti-PrP monoclonal antibody. This sufficed to block prion pathogenesis upon intraperitoneal prion inoculation (83). Passive immunization may be a useful strategy for prophylaxis of prion diseases, since it has been shown that passive transfer of anti-PrP monoclonal antibodies prior to the onset of clinical symptoms is able to delay the onset of prion disease in mice inoculated intraperitoneally (84). Unfortunately, several efforts aimed at active immunization strategies have met with little success due to the robust immune tolerance to $\operatorname{PrPC}^{\mathrm{C}}$. In this respect, it is certainly worth noting that extensive neuronal apoptosis in hippocampus and cerebellum has been shown following intracranial delivery of monoclonal antibodies reactive against a subset of $\operatorname{PrP}$ epitopes (85). The implications here are obvious; clearly, exhaustive in-vivo safety trials must be performed prior to the utilization of such strategies in humans.

\section{Soluble prionostatic candidates}

Do any serious candidates for prion therapeutic strategies exist? It is well established that expression of two $\mathrm{PrPC}^{\mathrm{C}}$ moieties that differ subtly from each other are able to inhibit prion replication (10). For example, humans heterozygous for a common $P R N P$ polymorphism at codon 129 are largely protected from CJD (86). Although the precise molecular basis for this effect is unclear, it is possible that heterologous $\mathrm{PrP}^{\mathrm{C}}$ may exert inhibitory action on prion replication by sequestration. This has been addressed directly by fusion of $\mathrm{PrP}^{\mathrm{C}}$ to an immunoglobulin $\mathrm{Fc} \gamma$ domain (87), allowing for ligand dimerization, expression of the molecule as a soluble moiety, and also, therefore, increased overall stability in body fluids. Transgenetic expression of this $\mathrm{PrP}-\mathrm{Fc}_{2}$ fusion protein resulted in significant prolongation of incubation period upon prion inoc- 
ulation via competition with $\mathrm{PrP}^{\mathrm{Sc}}$. It remains to be established whether $\mathrm{PrP}-\mathrm{Fc}_{2}$ is acting as an anti-prion compound when delivered exogenously. If so, soluble prion protein mutants may well represent anti-prion compounds.

\section{An outlook for prion therapy}

Prion diseases continue to present a diagnostic and therapeutic challenge to clinicians and researchers worldwide. There are many aspects of prion biology that remain unclear; we still do not know the precise physical nature of the infectious agent, the molecular and biochemical mechanisms underlying associated neurodegeneration, or the physiological function of $\operatorname{PrP}^{\mathrm{C}}$. The diagnostic tools currently available for prion diseases are signifi- cantly less sensitive and satisfactory than those available for other infectious diseases. Additionally, there is a dearth of therapeutic intervention strategies available for these diseases. However, that said, the last decade or so of prion research has witnessed astounding advances in our knowledge and understanding of basic prion biology, and the field has attracted increasing numbers of researchers from diverse disciplines. Undoubtedly, this trend will trigger further important advances in prion science.

Address correspondence to: Adriano Aguzzi, Institut für Neuropathologie, UniversitätsSpital Zürich, Schmelzbergstrasse 12, CH8091 Zurich, Switzerland. Phone: 41-1-255-2107; Fax: 41-1-2554402; E-mail: Adriano.Aguzzi@usz.ch.
1. Glatzel, M., et al. 2003. Human prion diseases: epidemiology and integrated risk assessment. Lancet Neurol. 2:757-763.

2. Collins, P.S., Lawson, V.A., and Masters, P.C. 2004. Transmissible spongiform encephalopathies. Lancet. 363:51-61.

3. Bolton, D.C., McKinley, M.P., and Prusiner, S.B. 1982. Identification of a protein that purifies with the scrapie prion. Science. 218:1309-1311.

4. Safar, J.G., et al. 2002. Measuring prions causing bovine spongiform encephalopathy or chronic wasting disease by immunoassays and transgenic mice. Nat. Biotechnol. 20:1147-1150.

5. Creutzfeldt, H.G. 1920. Über eine eigenartige herdförmige Erkrankung des Zentralnervensystems. Zeitschrift für die gesamte Neurologie und Psychiatrie. 57:1-19.

6. Jakob, A. 1921. Über eigenartige Erkrankungen des Zentralnervensystems mit bemerkenswertem anatomischem Befunde. (Spastische Pseudosklerose-Encephalomyelopathie mit disseminierten Degenerationsherden). Zeitschrift für die gesamte Neurologie und Psychiatrie. 64:147-228.

7. Griffith, J.S. 1967. Self-replication and scrapie. Nature. 215:1043-1044.

8. Prusiner, S.B. 1982. Novel proteinaceous infectious particles cause scrapie. Science. 216:136-144.

9. Weissmann, C. 1991. A 'unified theory' of prion propagation. Nature. 352:679-683.

10. Telling, G.C., et al. 1995. Prion propagation in mice expressing human and chimeric PrP transgenes implicates the interaction of cellular PrP with another protein. Cell. 83:79-90.

11. Priola, S.A., Chesebro, B., and Caughey, B. 2003. Biomedicine. A view from the top--prion diseases from 10,000 feet. Science. 300:917-919.

12. Glatzel, M., Abela, E., Maissen, M., and Aguzzi, A. 2003. Extraneural pathologic prion protein in sporadic Creutzfeldt-Jakob disease. N. Engl. J. Med. 349:1812-1820.

13. Hill, A.F., et al. 2003. Molecular classification of sporadic Creutzfeldt-Jakob disease. Brain. 126:1333-1346.

14. Aguzzi, A., Montrasio, F., and Kaeser, P.S. 2001. Prions: health scare and biological challenge. Nat. Rev. Mol. Cell Biol. 2:118-126.

15. Brown, K.L., et al. 1999. Scrapie replication in lymphoid tissues depends on prion protein- expressing follicular dendritic cells. Nat. Med. 5:1308-1312.

16. Aguzzi, A. 2003. Prions and the immune system: a journey through gut, spleen, and nerves. $A d v$. Immunol. 81:123-171.

17. Mabbott, N.A., Young, J., McConnell, I., and Bruce, M.E. 2003. Follicular dendritic cell dedifferentiation by treatment with an inhibitor of the lymphotoxin pathway dramatically reduces scrapie susceptibility. J. Virol. 77:6845-6854.

18. Prinz, M., et al. 2003. Oral prion infection requires normal numbers of Peyer's patches but not of enteric lymphocytes. Am. J. Pathol. 162:1103-1111.
19. Büeler, H.R., et al. 1993. Mice devoid of PrP are resistant to scrapie. Cell. 73:1339-1347.

20. Brandner, S., et al. 1996. Normal host prion protein necessary for scrapie-induced neurotoxicity. Nature. 379:339-343.

21. Blättler, T., et al. 1997. PrP-expressing tissue required for transfer of scrapie infectivity from spleen to brain. Nature. 389:69-73.

22. Brandner, S., et al. 1996. Normal host prion protein $(\mathrm{PrPC})$ is required for scrapie spread within the central nervous system. Proc. Natl. Acad. Sci. U. S. A. 93:13148-13151.

23. Kaeser, P.S., Klein, M.A., Schwarz, P., and Aguzzi, A. 2001. Efficient lymphoreticular prion propagation requires $\operatorname{prp}(\mathrm{c})$ in stromal and hematopoietic cells. J. Virol. 75:7097-7106.

24. Klein, M.A., et al. 1997. A crucial role for B cells in neuroinvasive scrapie. Nature. 390:687-690.

25. Klein, M.A., et al. 1998. PrP expression in B lymphocytes is not required for prion neuroinvasion. Nat. Med. 4:1429-1433.

26. Montrasio, F., et al. 2001. B lymphocyte-restricted expression of prion protein does not enable prion replication in prion protein knockout mice. Proc. Natl. Acad. Sci. U. S. A. 98:4034-4037.

27. Kitamoto, T., Muramoto, T., Mohri, S., Doh-Ura, K., and Tateishi, J. 1991. Abnormal isoform of prion protein accumulates in follicular dendritic cells in mice with Creutzfeldt-Jakob disease. J. Virol. 65:6292-6295.

28. Montrasio, F., et al. 2000. Impaired prion replication in spleens of mice lacking functional follicular dendritic cells. Science. 288:1257-1259.

29. Mabbott, N.A., Mackay, F., Minns, F., and Bruce, M.E. 2000. Temporary inactivation of follicular dendritic cells delays neuroinvasion of scrapie [letter]. Nat. Med. 6:719-720.

30. Klein, M.A., et al. 2001. Complement facilitates early prion pathogenesis. Nat. Med. 7:488-492.

31. Mabbott, N.A., Bruce, M.E., Botto, M., Walport, M.J., and Pepys, M.B. 2001. Temporary depletion of complement component $\mathrm{C} 3$ or genetic deficiency of $\mathrm{C} 1 \mathrm{q}$ significantly delays onset of scrapie. Nat. Med. 7:485-487.

32. Felten, D.L., and Felten, S.Y. 1988. Sympathetic noradrenergic innervation of immune organs. Brain Behav. Immun. 2:293-300.

33. Glatzel, M., Heppner, F.L., Albers, K.M., and Aguzzi, A. 2001. Sympathetic innervation of lymphoreticular organs is rate limiting for prion neuroinvasion. Neuron. 31:25-34.

34. Heinen, E., Bosseloir, A., and Bouzahzah, F. 1995. Follicular dendritic cells: origin and function. Curr. Top. Microbiol. Immunol. 201:15-47.

35. Forster, R., et al. 1996. A putative chemokine receptor, BLR1, directs B cell migration to defined lymphoid organs and specific anatomic compartments of the spleen. Cell. 87:1037-1047.

36. Prinz, M., et al. 2003. Positioning of follicular dendritic cells within the spleen controls prion neuroinvasion. Nature. 425:957-962.

37. Aguzzi, A., and Polymenidou, M. 2004. Mammalian prion biology. One century of evolving concepts. Cell. 116:313-327.

38. Mallucci, G., et al. 2003. Depleting neuronal PrP in prion infection prevents disease and reverses spongiosis. Science. 302:871-874.

39. Büeler, H.R., et al. 1992. Normal development and behaviour of mice lacking the neuronal cell-surface PrP protein. Nature. 356:577-582.

40. Mallucci, G.R., et al. 2002. Post-natal knockout of prion protein alters hippocampal CA1 properties, but does not result in neurodegeneration. EMBOJ. 21:202-210.

41. Ma, J., Wollmann, R., and Lindquist, S. 2002. Neurotoxicity and neurodegeneration when PrP accumulates in the cytosol. Science. 298:1781-1785.

42. Ma, J., and Lindquist, S. 2002. Conversion of PrP to a self-perpetuating PrPSc-like conformation in the cytosol. Science. 298:1785-1788.

43. Drisaldi, B., et al. 2003. Mutant PrP is delayed in its exit from the endoplasmic reticulum, but neither wild-type nor mutant PrP undergoes retrotranslocation prior to proteasomal degradation. J. Biol. Chem. 278:21732-21743.

44. Roucou, X., Guo, Q., Zhang, Y., Goodyer, C.G., and LeBlanc, A.C. 2003. Cytosolic prion protein is not toxic and protects against Bax-mediated cell death in human primary neurons. J. Biol. Chem. 278:40877-40881.

45. Hegde, R.S., et al. 1998. A transmembrane form of the prion protein in neurodegenerative disease. Science. 279:827-834.

46. Hegde, R.S., et al. 1999. Transmissible and genetic prion diseases share a common pathway of neurodegeneration. Nature. 402:822-826.

47. Shmerling, D., et al. 1998. Expression of amino-terminally truncated $\mathrm{PrP}$ in the mouse leading to ataxia and specific cerebellar lesions. Cell. 93:203-214.

48. Houston, F., Foster, J.D., Chong, A., Hunter, N., and Bostock, C.J. 2000. Transmission of BSE by blood transfusion in sheep. Lancet. 356:999-1000.

49. Hunter, N., et al. 2002. Transmission of prion diseases by blood transfusion. J. Gen. Virol. 83:2897-2905.

50. Aguzzi, A. 2000. Prion diseases, blood and the immune system: concerns and reality. Haematologica. 85:3-10.

51. Korth, C., et al. 1997. Prion (PrPSc)-specific epitope defined by a monoclonal antibody. Nature. 390:74-77.

52. Paramithiotis, E., et al. 2003. A prion protein epitope selective for the pathologically misfolded conformation. Nat. Med. 9:893-899.

53. Hsiao, K.K., et al. 1994. Serial transmission in rodents of neurodegeneration from transgenic mice expressing mutant prion protein. Proc. Natl. Acad. Sci. U. S. A. 91:9126-9130.

54. Lasmezas, C.I., et al. 1997. Transmission of the BSE agent to mice in the absence of detectable abnormal prion protein. Science. 275:402-405. 
55. Tagliavini, F., et al. 1994. Amyloid fibrils in Gerstmann-Straussler-Scheinker disease (Indiana and Swedish kindreds) express only PrP peptides encoded by the mutant allele. Cell. 79:695-703.

56. Duguid, J.R., and Dinauer, M.C. 1990. Library subtraction of in vitro cDNA libraries to identify differentially expressed genes in scrapie infection. Nucleic Acids Res. 18:2789-2792.

57. Duguid, J., and Trzepacz, C. 1993. Major histocompatibility complex genes have an increased brain expression after scrapie infection. Proc. Natl. Acad. Sci.U. S. A. 90:114-117.

58. Dandoy-Dron, F., et al. 1998. Gene expression in scrapie. Cloning of a new scrapie-responsive gene and the identification of increased levels of seven other mRNA transcripts. J. Biol. Chem. 273:7691-7697.

59. Miele, G., Manson, J., and Clinton, M. 2001. A novel erythroid-specific marker of transmissible spongiform encephalopathies. Nat. Med. 7:361-364.

60. Glock, B., et al. 2003. Transcript level of erythroid differentiation-related factor, a candidate surrogate marker for transmissible spongiform encephalopathy diseases in blood, shows a broad range of variation in healthy individuals. Transfusion. 43:1706-1710

61. Tribl, G.G., et al. 2002. Sequential MRI in a case of Creutzfeldt-Jakob disease. Neuroradiology. 44:223-226

62. Zeidler, M., Collie, D.A., Macleod, M.A., Sellar, R.J., and Knight, R. 2001. FLAIR MRI in sporadic Creutzfeldt-Jakob disease. Neurology. 56:282.

63. Hsich, G., Kinney, K., Gibbs, C.J., Lee, K.H., and Harrington, M.G. 1996. The 14-3-3 brain protein in cerebrospinal fluid as a marker for transmissible spongiform encephalopathies. N. Engl. J. Med. 335:924-930.

64. Beaudry, P., et al. 1999. 14-3-3 protein, neuron-specific enolase, and S-100 protein in cerebrospinal fluid of patients with Creutzfeldt-Jakob disease. Dement. Geriatr. Cogn. Disord. 10:40-46.

65. Zerr, I., et al. 1998. Detection of 14-3-3 protein in the cerebrospinal fluid supports the diagnosis of Creutzfeldt-Jakob disease. Ann. Neurol. 43:32-40.

66. Aguzzi, A., and Weissmann, C. 1997. Prion research: the next frontiers. Nature. 389:795-798.

67. Klohn, P.C., Stoltze, L., Flechsig, E., Enari, M., and
Weissmann, C. 2003. A quantitative, highly sensitive cell-based infectivity assay for mouse scrapie prions. Proc. Natl. Acad. Sci. U. S. A. 100:11666-11671.

68. Caughey, B., and Race, R.E. 1992. Potent inhibition of scrapie-associated PrP accumulation by congo red. J. Neurochem. 59:768-771.

69. Tagliavini, F., et al. 1997. Effectiveness of anthracycline against experimental prion disease in Syrian hamsters. Science. 276:1119-1122.

70. Caughey, B., and Raymond, G.J. 1993. Sulfated polyanion inhibition of scrapie-associated PrP accumulation in cultured cells. J. Virol. 67:643-650.

71. Priola, S.A., Raines, A., and Caughey, W.S. 2000. Porphyrin and phthalocyanine antiscrapie compounds. Science. 287:1503-1506.

72. Supattapone, S., et al. 2001. Branched polyamines cure prion-infected neuroblastoma cells. J. Virol. 75:3453-3461.

73. Soto, C., et al. 2000. Reversion of prion protein conformational changes by synthetic beta- sheet breaker peptides. Lancet. 355:192-197.

74. Caughey, B., et al. 2003. Inhibition of proteaseresistant prion protein accumulation in vitro by curcumin. J. Virol. 77:5499-5502.

75. Daude, N., Marella, M., and Chabry, J. 2003. Specific inhibition of pathological prion protein accumulation by small interfering RNAs. J. Cell. Sci. 116:2775-2779.

76. Sethi, S., Lipford, G., Wagner, H., and Kretzschmar, H. 2002. Postexposure prophylaxis against prion disease with a stimulator of innate immunity. Lancet. 360:229-230.

77. Frigg, R., Klein, M.A., Hegyi, I., Zinkernagel, R.M., and Aguzzi, A. 1999. Scrapie pathogenesis in subclinically infected B-cell-deficient mice. J. Virol. 73:9584-9588.

78. Prinz, M., et al. 2003. Prion pathogenesis in the absence of Toll-like receptor signalling. EMBO Rep. 4:195-199.

79. Heikenwalder, M., et al. 2004. Lymphoid follicle destruction and immunosuppression after repeated CpG oligodeoxynucleotide administration. Nat. Med. 10:187-192.

80. Peretz, D., et al. 2001. Antibodies inhibit prion propagation and clear cell cultures of prion infectivity. Nature. 412:739-743.

81. Enari, M., Flechsig, E., and Weissmann, C. 2001.
Scrapie prion protein accumulation by scrapieinfected neuroblastoma cells abrogated by exposure to a prion protein antibody. Proc. Natl. Acad. Sci. U. S. A. 98:9295-9299.

82. Souan, L., et al. 2001. Modulation of proteinase-K resistant prion protein by prion peptide immunization. Eur. J. Immunol. 31:2338-2346.

83. Heppner, F.L., et al. 2001. Prevention of scrapie pathogenesis by transgenic expression of antiprion protein antibodies. Science. 294:178-182.

84. White, A.R., et al. 2003. Monoclonal antibodies inhibit prion replication and delay the development of prion disease. Nature. 422:80-83.

85. Solforosi, L., et al. 2004. Cross-linking cellular prion protein triggers neuronal apoptosis in vivo. Science. 303:1514-1516.

86. Mead, S., et al. 2003. Balancing selection at the prion protein gene consistent with prehistoric kurulike epidemics. Science. 300:640-643.

87. Meier, P., et al. 2003. Soluble dimeric prion protein binds $\operatorname{Pr} \mathrm{P}(\mathrm{Sc})$ in vivo and antagonizes prion disease. Cell. 113:49-60.

88. Ladogana, A., et al. 1992. Sulphate polyanions prolong the incubation period of scrapie-infected hamsters. J. Gen. Virol. 73:661-665.

89. Prusiner, S.B., et al. 1983. Scrapie prions aggregate to form amyloid-like birefringent rods. Cell. 35:349-358.

90. Caughey, B., Ernst, D., and Race, R.E. 1993. Congo red inhibition of scrapie agent replication. J. Virol. 67:6270-6272.

91. Pocchiari, M., Schmittinger, S., and Masullo, C. 1987. Amphotericin B delays the incubation period of scrapie in intracerebrally inoculated hamsters. J. Gen. Virol. 68:219-223.

92. Mange, A., et al. 2000. Amphotericin B inhibits the generation of the scrapie isoform of the prion protein in infected cultures. J. Virol. 74:3135-3140.

93. Korth, C., May, B.C., Cohen, F.E., and Prusiner, S.B. 2001. Acridine and phenothiazine derivatives as pharmacotherapeutics for prion disease. Proc. Natl. Acad. Sci. U. S. A. 98:9836-9841.

94. Barret, A., et al. 2003. Evaluation of quinacrine treatment for prion diseases. J. Virol. 77:8462-8469.

95. Bach, S., et al. 2003. Isolation of drugs active against mammalian prions using a yeast-based screening assay. Nat. Biotechnol. 21:1075-1081. 